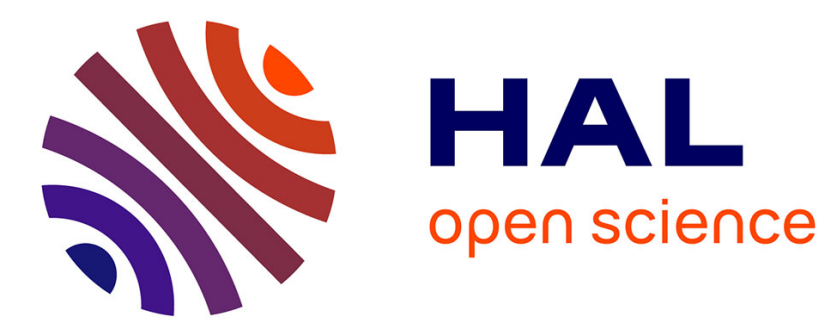

\title{
Force sensors based on screen-printed cantilevers
}

Riadh Lakhmi, Hélène Debéda, Isabelle Dufour, Claude Lucat

\section{To cite this version:}

Riadh Lakhmi, Hélène Debéda, Isabelle Dufour, Claude Lucat. Force sensors based on screen-printed cantilevers. IEEE Sensors Journal, 2010, 10 (6), pp.1133-1137. 10.1109/JSEN.2010.2040387 . hal00453483

\section{HAL Id: hal-00453483 \\ https://hal.science/hal-00453483}

Submitted on 13 Nov 2014

HAL is a multi-disciplinary open access archive for the deposit and dissemination of scientific research documents, whether they are published or not. The documents may come from teaching and research institutions in France or abroad, or from public or private research centers.
L'archive ouverte pluridisciplinaire HAL, est destinée au dépôt et à la diffusion de documents scientifiques de niveau recherche, publiés ou non, émanant des établissements d'enseignement et de recherche français ou étrangers, des laboratoires publics ou privés. 


\title{
Force sensors based on screen-printed cantilevers
}

\author{
Riadh LAKHMI, Hélène DEBEDA, Isabelle DUFOUR, Claude LUCAT
}

\begin{abstract}
In this paper, the design, the fabrication and the characterization of ceramic screen-printed force sensors are described. They are based on the use of cantilevers with integrated piezoresistors. The choice of the materials constituting the cantilever and the strain gauge, so as the dimensions of the cantilever have been optimized in order to measure forces in $\mathrm{mN}$ range. The sensors have been fabricated using the screenprinting technique associated with the sacrificial layer technique to release the free-standing part of the cantilevers. Afterwards, they have been characterized: measurement of sensitivity, reproducibility and materials properties (Young's modulus and strain gauge factor). The performances of these sensors are compared to the existing silicon, polymer and ceramic sensors.
\end{abstract}

Index Terms - cantilevers, ceramic, force sensor, piezoresistor, screen-printing.

\section{INTRODUCTION}

The microsystems, generally designated by MEMS (MicroElectroMechanical Systems), have been used for some years in the fields of micro-electronic, microrobotic, microfluidic, etc. Microcantilevers are common structures for MEMS, employed for different applications (mechanical sensors, gas sensors, AFM [1-4], etc.). Most of them are fabricated thanks to silicon micromachining. Nevertheless, other fabrication processes (ceramic, polymer based...) are attractive in terms of cost but also sensitivity or stability [5-8].

Low Temperature Cofired Circuits (LTCC) technology is an example of an alternative low cost ceramic process successfully applied for the fabrication of cantilever force sensors operating in $\mathrm{mN}$ range [7-8]. In this LTCC technology, the piezoresistive element integrated on the cantilever for the force measurement is a screen-printed thick film resistor. Another low cost process based on the association of standard screen-printing technology with the

Manuscript received October 23, 2009

R. Lakhmi is at the Universite de Bordeaux, IMS Laboratory, Microsystem group, Talence, F-33405, France (e-mail: riadh.lakhmi@ims-bordeaux.fr)

H. Debéda is at the Université de Bordeaux, IMS Laboratory, Microsystem group, Talence, F-33405, France (Phone : (33) 5400083 36; Fax : (33) 556 3715 45; e-mail: helene.debeda@ims-bordeaux.fr), corresponding author

I. Dufour is at the Université de Bordeaux, IMS Laboratory, Microsystem group, Talence, F-33405, France (e-mail: isabelle.dufour@ims-bordeaux.fr)

C. Lucat is at the Universite de Bordeaux, IMS Laboratory, Microsystem group, Talence, F-33405, France (e-mail: claude.lucat@ims-bordeaux.fr) sacrificial layer [9-10], is suggested for the fabrication of cantilevers devoted to new force sensors.

The purpose of this paper is to show the feasibility of such sensors, using screen-printed glass ceramic cantilevers and integrated thick film piezoresistor. Comparison of their performances with those of other ceramic sensors made with LTCC technology is proposed.

The first part of this paper describes the design of force sensors working in the $\mathrm{mN}$ range sensitivities needed for example in robotic applications [11]. The second part highlights the fabrication process of the sensors. Finally, the third part is dedicated to the materials characterization (Young's modulus of the cantilever and gauge factor of the piezoresistors) and the metrological sensor characterization.

\section{SENSOR DESIGN}

\section{A. Principle}

The cantilever force sensor principle and its dimensions are given in fig 1 .

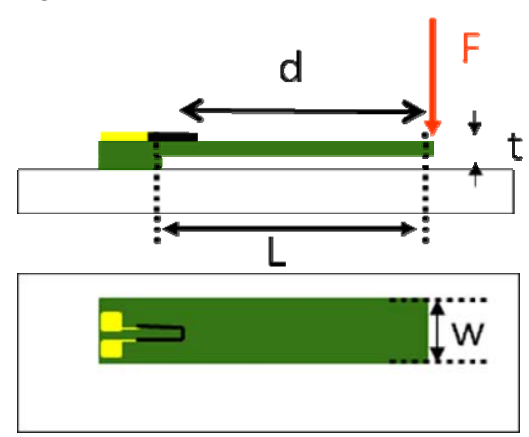

Fig 1. Geometry of cantilever structures

An applied force $F$ at the free-end induces a strain in the cantilever which is maximal closed to the clamped-end. The strain gauge integrated in this area enables the conversion of this strain into a resistance variation. The resistance variation induced by the applied force can be written [12]:

$$
\frac{\Delta R}{R}=G_{F} \varepsilon_{l}=G_{F} \frac{6 F d}{E t^{2} w}
$$

where $G_{F}$ is the intrinsic gauge factor of the strain gauge, $\varepsilon_{l}$ the longitudinal strain, $E$ the Young's modulus of the cantilever, $w$ its width, $t$ its thickness and $d$ the distance between the strain gauge and the application point of the force. 


\section{B. Cantilever choice (geometry and material)}

The sensor force range depends on the geometry of the cantilever but also on the parameters $E$ and $G_{F}$ which are linked to the materials and their fabrication process [13-15]. Table I illustrates for example the characteristics of different strain gauge materials. Compared to silicon or metallic strain gauges, the thick film resistors are a good compromise in terms of sensitivity but also stability.

TABLE I

CHARACTERISTICS OF STRAIN GAUGES MATERIALS

\begin{tabular}{ccccc}
\hline \hline Material & $\boldsymbol{G}_{\boldsymbol{F}}$ & $\begin{array}{c}\mathbf{T C R} \\
\left(\mathbf{p p m} /{ }^{\circ} \mathbf{C}\right)\end{array}$ & $\begin{array}{c}\mathbf{T C G F} \\
\left(\mathbf{p p m} /{ }^{\circ} \mathbf{C}\right)\end{array}$ & Stability \\
\hline $\begin{array}{c}\text { Metallic } \\
\text { sheets and } \\
\text { films }\end{array}$ & $1-2$ & 20 & 100 & Excellent \\
$\begin{array}{c}\text { Silicon single } \\
\text { crystals } \\
\begin{array}{c}\text { Thick Film } \\
\text { Resistors }\end{array}\end{array}$ & $50-80$ & 1000 & -1500 & Good \\
\hline \hline
\end{tabular}

The TCR (Temperature Coefficient Resistance) and the $T C G F$ (Temperature Coefficient of the Gauge Factor point out the influence of the temperature on the gauge resistance.

Taking into account the geometric limitations of the screen-printing technique and the screen-printed thick layer materials properties (glass-ceramic cantilever and strain gauge), we have calculated the sensitivities $S=\Delta R /(R F)$ for different sensor dimensions (table II). The range of $E$ and $G_{F}$ corresponds to what can be expected for glass-ceramic screenprinted materials. Those sensitivity values have been compared to those obtained for other existing cantilevers with piezoresistors (table III) [16]. The minimum detectable force linked to the electronic noise $(\Delta R / R$ minimum $=0.01 \%)$ has also been estimated.

TABLE II

CALCULATED SENSITIVITIES $S$ AND MINIMUM FORCE $F_{\text {MIN }}$ FOR DIFFERENT SIZES OF SCREEN-PRINTED CANTILEVERS

\begin{tabular}{|c|c|c|c|c|c|}
\hline & $\begin{array}{c}L(\mathrm{~mm}) \\
w(\mathrm{~mm}) \\
t(\mu \mathrm{m})\end{array}$ & $\begin{array}{c}15 \\
2 \\
50\end{array}$ & $\begin{array}{c}10 \\
3 \\
50\end{array}$ & $\begin{array}{c}15 \\
2 \\
100\end{array}$ & $\begin{array}{c}10 \\
3 \\
100\end{array}$ \\
\hline & $E=10 \mathrm{GPa} /$ & 63 & 28 & 16 & 7.0 \\
\hline & $\begin{array}{c}E=100 \mathrm{GPa} / \\
G_{F}=2\end{array}$ & 0.35 & 0.15 & 0.10 & 0.05 \\
\hline & $\begin{array}{c}E=10 \mathrm{GPa} / \\
G_{F}=35\end{array}$ & 1.6 & 3.5 & 6.3 & 14 \\
\hline $1 x^{2}$ & $\begin{array}{c}E=100 \mathrm{GPa} / \\
G_{F}=2\end{array}$ & 276 & 624 & 1108 & 2500 \\
\hline
\end{tabular}

TABLE III

COMPARISON WITH EXISTING CANTILEVER FORCE SENSORS WITH PIEZORESISTORS

\begin{tabular}{|c|c|c|c|c|}
\hline $\begin{array}{l}\text { Cantilever } \\
\text { nature }\end{array}$ & $\begin{array}{c}L / w / t \\
(\mathrm{~mm} / \mathrm{mm} / \mu \mathrm{m})\end{array}$ & $\begin{array}{c}E / G_{F} \\
\left(\mathrm{GPa} / \text { - }^{-}\right)\end{array}$ & $S\left(\mathrm{~N}^{-1}\right)$ & $F_{\min }$ \\
\hline \multirow{2}{*}{ Silicon $\mathrm{Si}$} & $1 / 0.35 / 100$ & $180 / 50$ & 0.5 & $1 \mathrm{mN}$ \\
\hline & $0.35 / 0.03 / 0.34$ & $100 / 65$ & 393598 & $7 \mathrm{pN}$ \\
\hline SU8 Polymer & $0.22 / 0.28 / 1.5$ & $4.5 / 2$ & 931 & - \\
\hline LTCC Ceramic & $15 / 3 / 130$ & $150 / 10$ & 0.118 & $10 \mathrm{mN}$ \\
\hline Alumina $\mathrm{Al}_{2} \mathrm{O}_{3}$ & $15 / 3 / 250$ & $330 / 10$ & 0.015 & $200 \mathrm{mN}$ \\
\hline $\begin{array}{l}\text { Screen-printed } \\
\text { glass-ceramic } \\
\text { cantilevers }\end{array}$ & \multicolumn{2}{|c|}{ see table II } & $0.05-63$ & $1.6 \mu \mathrm{N}-2.5 \mathrm{mN}$ \\
\hline
\end{tabular}

The results clearly show that the screen-printing technique can not compete with other techniques (silicon, polymer) in terms of sensitivity. They nevertheless present better sensitivities than other ceramic techniques (alumina or LTCC), and, as for the above ceramic technologies, they are interesting in terms of costs and reliability. Indeed, they have a good stability towards harsh environments (temperature, bases, acids...). Moreover, it is possible to realize a hybrid microsystem integrating the sensor and its electronic thanks to the standard thick film technology [17].

\section{Strain gauge design}

The geometry adopted for the strain gauge is given fig 2 . It is a classical geometry used in silicon force sensors [18] and it derives from the "streamer" geometry mainly used for metallic gauges. The dimensions of $l, b, x$ and $e$ are respectively $2.67 \mathrm{~mm} / 1.52 \mathrm{~mm} / 0.25 \mathrm{~mm} / 0.25 \mathrm{~mm} \quad(0.105 \mathrm{in} / 0.060 \mathrm{in} /$ 0.010in /0.010in) and are compatible with thick film technology.

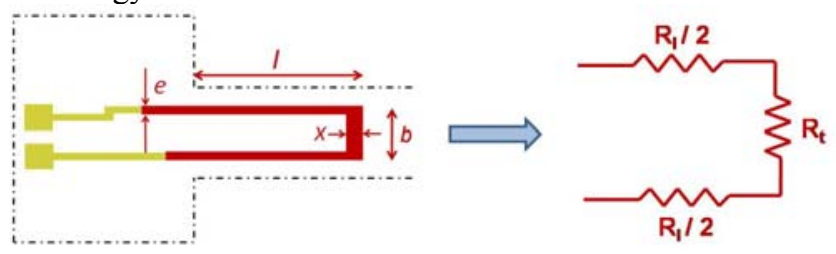

Fig 2. Geometry of the strain gauge and equivalent circuit

The adhesion between the piezoresistive layer and the structural layer is supposed to be perfect. In those conditions, the strain gauge's longitudinal branches will follow the cantilever's longitudinal strain and the transversal branches will follow the cantilever's transversal strain:

$$
\begin{gathered}
\frac{\Delta R_{l}}{R_{l}}=G_{F} \varepsilon_{l} \\
\frac{\Delta R_{t}}{R_{t}}=G_{F} \varepsilon_{t}=-G_{F} \nu_{0} \varepsilon_{l}
\end{gathered}
$$

where $R_{l}$ and $R_{t}$ are respectively the longitudinal and transversal branch resistances (fig. 2), $\varepsilon_{l}$ and $\varepsilon_{t}$ are respectively the cantilever's longitudinal and transversal strain and $v_{0}$ its Poisson coefficient.

Considering the expressions (2) and (3), the output signal can be expressed the following way: 


$$
\frac{\Delta R}{R}=G_{F} \varepsilon_{l} \frac{1-v_{0} \alpha}{1+\alpha}
$$

where $\alpha$ is the ratio between $R_{t}$ and $R_{l}$.

The intrinsic gauge factor $G_{F}$ of a material (semiconductor, metallic or thick film) does not take in account the geometry of the gauge. From the relation (4), the effective gauge factor $K_{j}$ can be extrapolated:

$$
K_{j}=G_{F} \frac{1-v_{0} \alpha}{1+\alpha}
$$

Considering a Poisson ratio $v_{0}=0.2$, an effective gauge factor $K_{j}=0.73 G_{F}$ is found for the chosen dimensions of the screen-printed gauge. The equation (5) shows the importance of the strain gauge geometry on the sensor performances.

\section{FABRICATION PROCESS}

\section{A. Screen-printing}

The screen-printing process is widely used in hybrid microelectronic for the fabrication of interconnections, thick layer passive components (conductors, resistors, dielectrics...) and the packaging of hybrid circuits. It enables the realization of any pattern (minimum line width $100 \mu \mathrm{m}$ ) with a controlled thickness (from a few micrometers to a few tens of micrometers per deposit). Thick layers are generally screenprinted on alumina substrate.. Once it is screen-printed, the ink is dried at $120^{\circ} \mathrm{C}$ and then fired at high temperature (classically $850^{\circ} \mathrm{C}$ ) to give the layer its final electrical and mechanical properties (adhesion to the substrate, cohesion thanks to the sintering) [17].

The standard thick film process has been associated to the sacrificial layer technique for the obtaining of free-standing structures. The sacrificial layer, used as a support for the deposition of the active layer, is removed at the end of the process in order to set the active layer free from the substrate. The sacrificial layer is realized at the IMS laboratory from a polymer ink epoxy type loaded with strontium carbonate $\left(\mathrm{SrCO}_{3}\right)$. After the screen-printing step, the layer is polymerized at $120^{\circ} \mathrm{C}$ before the printing of the active layer. The samples are fired at temperature above $850^{\circ} \mathrm{C}$. Then, the sacrificial layer is removed by dissolution in an acid phosphoric $\left(\mathrm{H}_{3} \mathrm{PO}_{4}\right)$ solution $(\mathrm{pH}=1)$ [9].

\section{B. Application to cantilever type force sensor}

The following materials have been chosen for the sensor fabrication:

- $\quad$ an alumina substrate $\left(96 \% \mathrm{Al}_{2} \mathrm{O}_{3}\right)$ is used as a support for the structures. The substrate has been pre-cut by laser for the collective fabrication of sensors.

- a glass-ceramic ink has been used for the cantilever because of its good dielectric properties, its good aptitude to sintering, its good adherence to the alumina substrate and its relatively low Young's modulus (a few tens of GPa). The dielectric ink from
ElectroScience Laboratory ESL4702, mainly based on alumina, silica and barium oxide, has been chosen.

- the strain gauge, realized from a resistive ink (ESL3414), has been chosen for its piezoresistive properties $\left(G_{F}=17, T C R \approx \pm 100 \mathrm{ppm} /{ }^{\circ} \mathrm{C}\right.$, resistance per square $R_{\text {/口 }} \approx 4 \mathrm{k} \Omega / \square$ for a thickness of $10 \mu \mathrm{m}$ ).

- the gauge electrical contacts are realized with the conductive gold ink ESL8836.

The fabrication steps are described in fig 3 . The different layers of the sensor have been successively screen-printed with a drying at $120^{\circ} \mathrm{C}$ between each deposit. A co-firing at $850^{\circ} \mathrm{C}$ has been performed once all the layers have been printed.

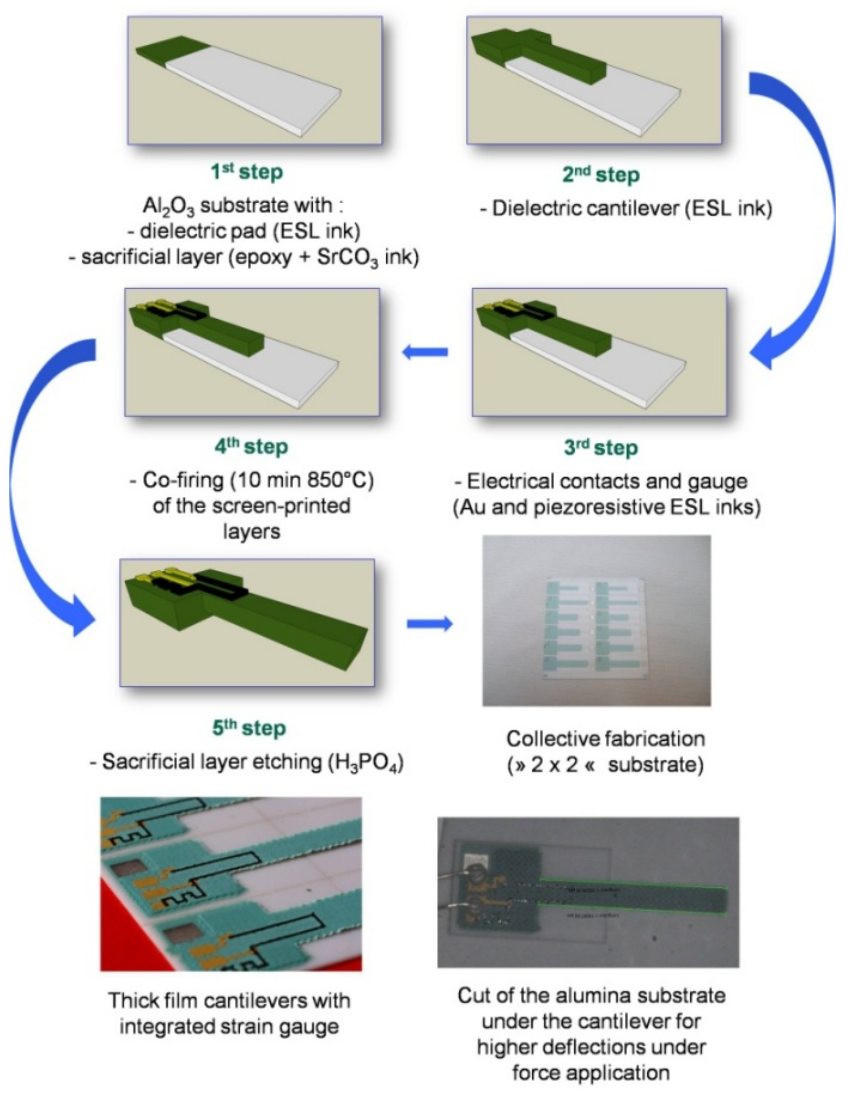

Fig 3. Fabrication steps of the force sensor

In fig 3, we can notice the presence of two piezoresistors on the cantilever: the active gauge described part II-C integrated in the free-standing part of the cantilever, and the passive one placed on the fixed part of the cantilever. These resistances can be integrated in a Wheatstone bridge to eliminate temperature effect.

\section{CHARACTERIZATION OF THE FORCE SENSOR}

\section{A. Experimentation}

Applications of known forces $F$ at a distance $0.5 \mathrm{~mm}$ from the free-end of the cantilever allows the determinations of sensitivity $S=\Delta R /(R F)$, Young's modulus $E$ and gauge factor 
$K_{j}$. The force is either obtained thanks to home-calibrated $\mathrm{SnAgCu}$ solder balls (from $20 \mathrm{mg}$ to $430 \mathrm{mg}$ ) or thanks to the stylus of a mechanical Tencor profilometer (from $5 \mathrm{mg}$ to $100 \mathrm{mg}$ ). During the force application, the deflection is measured with an optical profilometer Altisurf 500 (range $3 \mathrm{~mm}$, resolution $0.5 \mu \mathrm{m})$. This deflection, which depends on the stiffness of the material and consequently on $E$, is given by the following relationship [12]:

$$
\delta=G_{F} \frac{4 L^{3} F}{E t^{3} w}
$$

The Young' modulus can be thus calculated, providing that cantilever's dimensions are accurately known.

The dimensions $L, w$ and $t$ used in the calculations are measured by two methods. The length of the cantilever and its width are obtained thanks to the Altisurf 500 optical profilometer (range $300 \mu \mathrm{m}$, resolution $0.1 \mu \mathrm{m}$ ). The thickness is estimated with a manual micrometer (resolution $\pm 2 \mu \mathrm{m}$ ). The cantilever roughness $(\mathrm{R}=4.5 \pm 1.2 \mu \mathrm{m})$ and the micrometer resolution induce an uncertainty on the thickness measurement evaluated to $5 \mu \mathrm{m}$.

\section{B. Material characterization ( $E$ and $K_{j}$ )}

Young's modulus and gauge factor are respectively obtained thanks to the slope measurement of the curve $F(\delta)$ (fig 4) and the curve $\Delta R / R(\varepsilon)$.

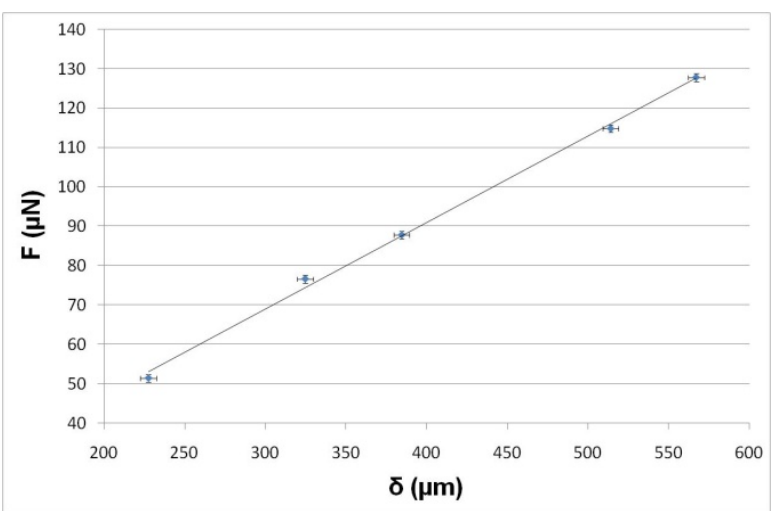

Fig 4. Applied force $F$ as a function of the cantilever free-end deflection $\delta$

The determined mean Young's modulus is $36 \mathrm{GPa} \pm 4 \mathrm{GPa}$ [19]. The mean value measured for the effective gauge factor is $K_{j}=11.8 \pm 0.9$ is closed to the calculated one $K_{j}=12.1$ (from the constructor data $G_{F}=17$ ).

\section{Metrological sensor characterization}

The main static metrological characteristics, among which the detectable forces range, the hysteresis, the linearity and the sensitivity, have been determined.

The limit of force detection is chosen when the ratio (signal noise /resistance variation) reaches $50 \%$ (fig 5). The minimum and the maximum detectable forces are linked to the cantilever dimensions. Minimum detectable forces of $100 \mu \mathrm{N}$ have been determined.

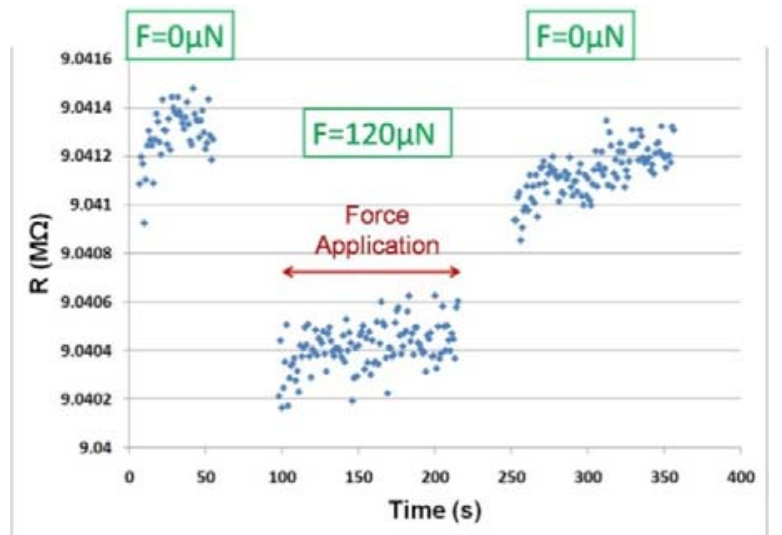

Fig 5. Resistance measurement during the application of a force $F$ on the tip cantilever (stylus test)

Besides, the maximum detectable force (also called scale load),defined as the limit force for which the sensor properties are guaranteed are close to $4 \mathrm{mN}$ for the chosen cantilever dimensions. Indeed, for most of them, the properties are guaranteed even for a force corresponding to $4.3 \mathrm{mN}$; but a few ones break under this last force value.

The resistance variation of the strain gauge, consecutive to the force application, has been evaluated for increasing and decreasing forces varying in the range $0.2-4.3 \mathrm{mN}$ (fig. 6). An hysteresis value of $1.7 \%$ and a linearity error of $3.5 \%$ have been found.

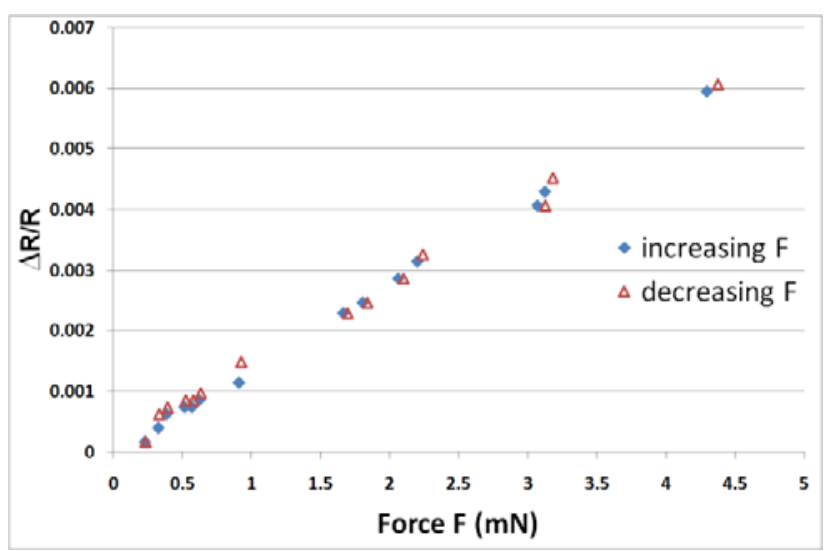

Fig 6. Cantilever hysteresis evaluation (cantilever dimensions: $10 \mathrm{~mm} / 2 \mathrm{~mm} / 75 \mu \mathrm{m})$

Sensors sensitivities deduced from the slope of the curve $\Delta R / R=f(F)$ have been determined for different cantilever dimensions (table IV). Within the range $0.97-2.33 \mathrm{~N}^{-1}$, measured sensitivities match the predicted ones except for the P6 cantilever. For this cantilever, the measured gauge factor is $K_{j}=10$, whereas the calculations gives $K_{j}=12.1$. 
TABLE IV

MEASURED AND CALCULATED SENSITIVITIES FOR DIFFERENT CANTILEVER DIMENSIONS

\begin{tabular}{lcccccc}
\hline \hline $\begin{array}{c}\boldsymbol{L} / \boldsymbol{w} / \boldsymbol{t} \\
(\mathbf{m m} / \mathbf{m m} / \mathbf{\mu m})\end{array}$ & $\begin{array}{c}12 / 3 / 80 \\
(\mathrm{P} 5)\end{array}$ & $\begin{array}{c}10 / 3 / 75 \\
(\mathrm{P} 3)\end{array}$ & $\begin{array}{c}11 / 3 / 75 \\
(\mathrm{P} 4)\end{array}$ & $\begin{array}{c}15 / 3 / 80 \\
(\mathrm{P} 6)\end{array}$ & $\begin{array}{c}10 / 2 / 75 \\
(\mathrm{P} 1)\end{array}$ & $\begin{array}{c}15 / 2 / 75 \\
(\mathrm{P} 2)\end{array}$ \\
\hline$S_{\text {measured }}$ (mass) & 0.97 & 1.01 & 1.06 & 1.08 & 1.38 & 2.33 \\
$\left(\mathrm{~N}^{-1}\right)$ & \pm 0.09 & \pm 0.09 & $\begin{array}{c} \pm 0.09 \\
\pm 0.08\end{array}$ & \pm 0.09 & \pm 0.12 \\
$S_{\text {measured }}$ & - & - & 1.13 & - & - & - \\
$($ stylus $)\left(\mathrm{N}^{-1}\right)$ & - & & \pm 0.09 & - & & \\
$\begin{array}{l}S_{\text {calculated }}\left(\mathrm{N}^{-1}\right) \\
(\mathrm{E}=36 \mathrm{GPa}\end{array}$ & 1.02 & 0.92 & 1.04 & 1.34 & 1.39 & 2.28 \\
$\left.\mathrm{~K}_{\mathrm{j}}=12.1\right)$ & & & & & & \\
\hline \hline
\end{tabular}

The fabrication reproducibility has been evaluated on 3 cantilevers P2 type. A good reproducibility linked to the fabrication process is observed (fig 7). The differences are related to the uncertainty on cantilever dimensions but also to measurement uncertainties related to the application point.

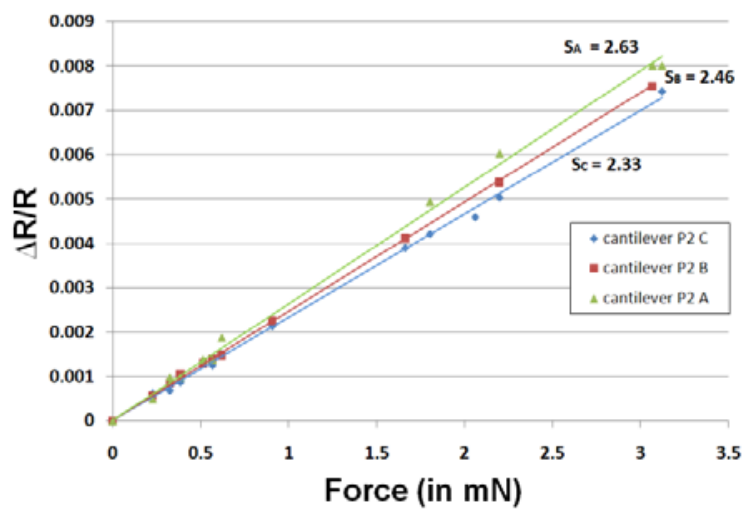

Fig 7. Fabrication reproducibility of the $\mathrm{P} 2$ type cantilevers $(15 \mathrm{~mm} / 2 \mathrm{~mm} / 75 \mu \mathrm{m})$

\section{CONCLUSION}

The feasibility of force sensors based on screen-printed glass ceramic cantilevers with the low cost thick film process has been demonstrated. Compared to ceramic LTCC cantilevers force sensors, sensors studied in this paper exhibit a lower measurable force of $100 \mu \mathrm{N}$ [8]. Moreover, good fabrication reproducibility has been observed.

The size and the shape of cantilevers could be optimized with the main objective of forces detection in $\mathrm{mN}$ range and to improve the sensitivity [20-21]. According to the resolution obtained with screen-printing process, width of $100 \mu \mathrm{m}$ and thickness of a few microns are reasonable for our cantilever. This size reduction should allow a better integration in microsystems. In agreement with microrobot application [11], where the microgripper are made with different micromachining technologies, our process could be a simple and cost effective alternative process, for a whole "screenprinted microrobot" fabrication [10].

\section{REFERENCES}

[1] X. Li, D. Su, Z. Zhang, A novel technique of microforce sensing and loading, Sensors and Actuators A: Physical, Vol. 153, pp. 13-23, 2009.
[2] E. Peiner, L. Doering, Force calibration of stylus instruments using silicon microcantilevers, Sensors and Actuators A: Physical, Vol. 123-4, pp. 137-145, 2005 .

[3] N.V. Lavrik, M.J. Sepaniak, P.G. Datskos, Cantilever transducers as a platform for chemical and biological sensors, Review of Scientific Instruments, Vol. 75, No. 3, pp. 2229-2253, 2004.

[4] K.M. Goeders, J.S. Colton, L.A. Bottomley, Sensing chemical interactions via mechanical motion, Chemical Reviews, Vol. 108, pp.522-542, 2008.

[5] A. Johansson , M. Calleja, P.A. Rasmussen, A. Boisen, SU-8 cantilever sensor system with integrated readout, Sensor and Actuator A: Physical,Vol. 123-124, pp. 111-1152005.

[6] J. Thaysen, A.D. Yalcinkaya, R.K. Vestergaard, S. Jensen, M.W. Mortensen, P. Vettiger, A. Menon, SU-8 Based Piezoresistive Mechanical Sensor, Proceedings IEEE MEMS Conference 2002.

[7] H. Birol, T. Maeder, C. Jacq, G. Corradini, M. Boers, S. Sträsler, P. Ryser, Structuration and fabrication of sensors based on LTCC (Low Temperature Co-fired Ceramic) Technology, Key Engineering Materials Vols. 336-338, pp 1849-1852, 2007.

[8] H. Birol, T. Maeder, I. Nadzeyka, M. Boers, P. Ryser, fabrication of a millinewton force sensor using low temperature co-fired ceramic (LTCC) technology, Sensors and actuators A : Physics, Vol. 134, pp.334-338, 2007

[9] C. Lucat, P. Ginet, F. Ménil, , New Sacrificial Layer Based ScreenPrinting Process for Free-Standing Thick-Films Applied to MEMS, International Journal of microelectronic and electronic packaging, 4, 86-92, 2007.

[10] C. Castille, C. Lucat, P. Ginet, F. Ménil, M. Maglione, Free-standing piezoelectric thick-films for MEMS applications, Proc. IMAPS/ACerS $4^{\text {th }}$ International Conference on Ceramic Interconnect and Ceramic Microsystems Technologies, Münich, April 21-24, 2008.

[11] R. Perez, N. Chaillet, K. Domanski, P. Janus, P. Grabiec, Fabrication, modeling and integration of a silicon technology for sensor in a piezoelectric micro-manipulator, Sensors and actuators A : Physical, Vol. 128, pp 367-375, 2006.

[12] S.P. Timoshenko, Strength of Materials, Part 1: Elementary Theory and Problems ( $2^{\text {nd }}$ edition $), D$. Van Nostrand Company, pp.88-170, 1968.

[13] M.F. Ashby, D.R.H. Jones, Engineering Materials II (3 $3^{\text {rd }}$ edition), Elsevier (2008), 464p.

[14] C.H. Cho, Characterization of Young's modulus of silicon versus temperature using a "beam deflection" method with a four-point bending fixture, Current Applied Physics, Vol 9, pp. 538-545, 2009.

[15] M. Prudenziati, Thick film sensors and actuators 1, 1994, ed. Elsevier Science BV, Amsterdam.

[16] H. Debéda, I. Dufour, P. Ginet, C. Lucat, Potentialities of piezoresistive cantilever force sensors based on free standing thick films, Mechatronics (2008), Le Grand Bornand (France).

[17] M. Haskard, K. Pitt, Thick film technology and applications, Electrochemical publications, 1997.

[18] A.A. Barlian, W.T. Park, J.R. Mallon, A.J. Ra stegar, B.L. Pruitt, Review: Semiconductor Piezoresistance for Microsystems, Proceedings of the IEEE Vol. 97, No. 3, pp513-552, March 2009.

[19] R. Lakhmi, H. Debéda, I. Dufour, C. Lucat, Determination of Young's Moduli for free-standing screen-printed thick film layers used in MEMS, 20th workshop on micromachining, micro mechanics and micro systems, Toulouse : France (2009) 
[20] P.R. Wilkinson, W.S. Klug, B. Van Leer, J.K. Gimzewski, Nanomechanical properties of piezoresistive cantilevers: Theory and experiment, Journal of Applied Physics, Vol. 104, $\mathrm{n}^{\circ} 10,2008$.

[21] J.A. Harley, T.W. Kenny, High-sensitivity piezoresistive cantilevers under 1000 A thick, Applied Physics Letters, Vol. 75, n 2, 1999. 